\title{
Assessment and Modeling of GSM Signal Propagation in Uyo, Nigeria
}

\author{
Sunny Orike, Promise Elechi, and Iboro Asuquo Ekanem
}

\begin{abstract}
High quality of service is a paramount concern in wireless networks. One of the strategies in achieving optimal performance is to use wireless empirical models to predict wireless link quality factors such as path loss and the received power in any given transmission domain with irregular terrain. The primary goal of this study is to develop a radio wave propagation model for Uyo metropolis. An assessment was carried out in three major roads within the city of Uyo in Akwa Ibom State, to determine the quality of GSM signal reception by measuring the signal field strength, magnetic field strength, and power density of the base transceiver stations. The measurements were carried out using radio frequency electromagnetic field strength meter over a distance of 2000 meters from the base stations. The results of the measurements were analysed and a path loss model was developed for Uyo using linear regression model. Three empirical models: Okumura-Hata model, COST-Hata model, and Egli model were also applied in predicting the path loss in Uyo and the results obtained were compared with the developed model for Uyo metropolis. The comparison showed that Route D model had a better comparison factor with the developed model while the Okumura-Hata and COST-Hata were almost the same with more loss as the distance increased. In all the measurements, the standard deviation was between $3.31 \mathrm{~dB}$ and $3.36 \mathrm{~dB}$.
\end{abstract}

Index Terms-GSM; Electromagnetic; BTS; Path Loss; Field Strength; Signal.

\section{INTRODUCTION}

Global System for Mobile Communication (GSM) is one of the inventions with speedy growth and the most demanding telecommunication applications in the world today [6]. The power density of GSM signal depends on three main factors: the transmitted power of the base transceiver station, the distance between the base transceiver station (BTS) and the mobile phone, and the obstacles within surrounding. Most electromagnetic radiation analysis was based and dependent on the maximum transmission power from the base transceiver station and the surrounding barriers in relation to their distance from the transmitter, as described by [4] and [5] utilized the data of electromagnetic propagation in buildings and developed a model to predict base station electromagnetic signal path loss in buildings. Moreover, the accurate calculation has been developed and analysed based on time variability of electric field level in GSM network downlink channels. A GSM BTS transmitted power is not always constant and at maximum, this is

Published on November 30, 2017.

S. Orike is the Head of the Department of Electrical Engineering, Rivers State University, Port Harcourt, Nigeria.

P. Elechi is a lecturer with the Department of Electrical Engineering, Rivers State University, Port Harcourt, Nigeria. (+234-8035476478; e-mail: elechi.promise@ust.edu.ng).

I.A. Ekanem is an M.Tech student of the Department of Electrical Engineering, Rivers State University, Port Harcourt, Nigeria. because of the time division multiplexing access (TDMA) techniques adopted by the GSM [21]. The transmitted power of a GSM base station is largely variable [4]. Hence, the worst-case assessment approach often overestimates electromagnetic field radiation exposure in actual conditions and overlooks the relation between the power transmitted by the base transceiver stations, the channel traffic, and the distance between the transmitter and the receiver. However, no statistical analyses have been established based on the transmitted power variation, although, some authors have established some calculation of the BTS transmitted power and electromagnetic radiation with respect to distances.

The number of cell towers in Uyo, Nigeria has increased tremendously towards providing adequate services to GSM subscribers. The cell towers are randomly situated everywhere in the town and as such not much consideration has been directed towards their disadvantages especially as one moves away from the base transceiver station. It has been observed that in Uyo, the GSM signal attenuates as one moves farther away from the Base transceiver station mast. The problem may lie in understanding the maximum distance that is permitted for a subscriber to move away from the base transceiver station in order to maintain high signal quality.

The aim of this work is to analyse and develop a model for predicting GSM signal propagation from Base Transceiver Stations in Uyo, Nigeria.

\section{LITERATURE REVIEW}

\section{A. Review of Related Work}

There have been many studies on the analysis of GSM signal radiations emanating from the base transceiver stations. Some have looked at these radiations in terms of their health implications while some have considered on different ways to improve on the signal quality for the purpose of effective communication system.

Various research works have been carried out on similar topics in the past, some of which include; analysis of radio wave propagation in Lagos and its environs [23], where signal measurements were carried out at Imota village, Epe town and Lekki area of Lagos State. The path loss values were estimated and compared with existing model. Another similar work was carried out for Akure metropolis in Ondo State Nigeria by [10].

Reference [15] worked on the prediction and optimization of signal path loss for urban environment using Hata model at $800 \mathrm{MHz}$. An optimized path loss model was developed based on the measurement collected in the Code Division Multiple Access (CDMA) network in the city of Benin, Edo State, Nigeria. 
Reference [3] worked on radio propagation in rural residential area with vegetation where measurements were performed in three rural locations in Poland; Lipniki, Koscierzyna and Tarczyn. Comparison was made between the experimental data and 3D-Stochastic model and the results showed close relationship between them with a rootmean-square of 0.274 .

Reference [2] worked on a forested environment of Idanre-Apomu axis of Ondo State, Nigeria. The path loss estimation was based on measurement of UHF signal strength for two seasons and was validated against theoretical estimations. The results showed a decreasing trend of signal strength as the distance was increased. Also, the high terrain showed increased path loss which was attributed to the high hills in the environment.

Reference [10] again worked on the mechanism of radio frequency propagations and empirical models for hilly terrain. Signal strength measurements were carried out in Idanre town of Ondo State, Nigeria leading to the development of a modified Cost 231-Hata model and was implemented with matlab graphical user interface for simulation.

Reference [19] measured the electromagnetic radiation in the University of Nigeria, Nsuka campus using EMF meter. The results provided information on the level of signal radiation in University of Nigeria environment. The results also showed that locations such as Odim recorded the maximum power density of $0.1879 \mathrm{~mW} / \mathrm{m} 2$, as the PG recorded the minimum power density of $0.0158 \mathrm{~mW} / \mathrm{m} 2$. The maximum power density was recorded at a distance of $200 \mathrm{~m}$ away from the foot of base station antenna.

Reference [4] investigated the effect of building on the GSM signals of MTN, Glo, Airtel and Etisalat using radio frequency signal tracker to conduct measurements on five (5) different building made with different materials (mud building with thatched roof, mud building/rusted corrugated iron sheet roof, sandcrete building/rusted corrugated iron sheet roof, sandcrete building/unrusted corrugated iron sheet roof and building with alucoboard wall cladding) in Rivers State, Nigeria. The results obtained were compared to the Okumura, HATA and COST-231 models and it showed that building with alucoboard wall cladding had the highest signal penetration loss while the sandcrete building/unrusted corrugated iron sheet roof had the lowest signal penetration loss, all measurements values corresponding to the Okumura model. For each of the network and environment considered, the path loss exponent varied between 3.06 to 4.59 and the standard deviation between $11.1 \mathrm{~dB}$ to $11.6 \mathrm{~dB}$.

Reference [6] developed a model to predict signal penetration through building walls. The model was developed using the principles of Fresnel Refraction Coefficient and the knife-edge diffraction. The total signal loss from the transmitter to the receiver was developed and modelled as the combination of three different effects; freespace propagation loss from the transmitter to building; the material penetration loss was modelled as the combination of the wall penetration loss and the diffraction loss. The results showed that despite the condition of the building walls, movement of people in the environment/room also affected the wireless signal quality as well as the chairs and gadgets in the room. The indoor signal path loss in the rooms increased from when the walls were plastered and continued until when the walls were covered with curtains, both rooms reduced by $4 \mathrm{dBm}$. The mean squared error ranged between $1.6 \mathrm{dBm}$ and $2.1 \mathrm{dBm}$ with a standard deviation between 11.1 and 11.5.

In all the literature considered, there has not been any model to predict GSM signal variation in South-South Nigeria. This is because the terrain is different from those locations considered. Hence, the need for this study aimed at formulating a predictive model for the region.

\section{B. Propagation in Free Space}

To make an estimate of the possibilities for a radio system to function, it is important to set up a link budget [20]. Due to the challenges/difficulty of making an accurate estimate of all the required parameters in signal processing from the transmitter to the receiver, it is often ideal to use simplified models. The Friis' Free Space Formula is mostly applied to determine the received signal from a transmitter considering the distance of separation and the antenna parameters [21]. It can be expressed as:

$P_{R}=\frac{P_{T} G_{T} G_{R} \lambda^{2}}{L_{T} L_{R}(4 \pi d)^{2}}$

where: $P_{R}$ is the Received power, $P_{T}$ is the Transmitted power, $G_{R}$ is the Receiver antenna gain, $G_{T}$ is the Transmitter antenna gain, $L_{R}$ is the Receiver losses, $L_{T}$ is the Transmitter losses, $\lambda$ is the Signal wavelength and $d$ is the Distance between transmitter and receiver antennas. In separating the parameters related to the radio system, (1) can be rearranged to [30]:

$\left(\frac{\lambda}{4 \pi d}\right)^{2}=\frac{P_{R} L_{R} L_{T}}{P_{T} G_{R} G_{T}}$

The expression on the left hand side the reciprocal of the signal path loss. The path loss is proportional to the square of the distance, $d$, between the transmitter and the receiver and inversely proportional to the square of the wavelength, $\lambda$.

$$
\text { Free Space Path Loss }=\left(\frac{4 \pi d}{\lambda}\right)^{2}
$$

The free space path loss can be expressed in decibel as [21], [4]:

$L_{F S P}=20 \log \left(\frac{4 \pi d}{\lambda}\right)$

\section{Path Loss}

Path loss is commonly used in signal propagation and wireless communications. It is the reduction in the power density of an electromagnetic wave as it propagates through space. It is a major component in the analysis and design of the link budget of a telecommunication system. Path loss can be caused by many factors such as reflection, diffraction, refraction, free space loss, aperture-medium coupling loss, and absorption [30]. It is also influenced by terrain contours, and environment, propagation medium, the distance between the transmitter and the receiver, and the height and location of antennas [6] and [29]. The causes of 
path loss include signal propagation loss caused by the natural expansion of the radio wave front in free space, absorption loss (sometimes called penetration loss) [6]. It is usually expressed in $\mathrm{dB}$.

\section{Path Loss Models}

There are many empirical outdoor propagation path loss models such as Longley-Rice model, Durkin's model, Okumura model, Hata model etc, and indoor propagation models such as ITU model, etc. In this work, emphasis will be on the ITU model since this work is based on determining indoor loss. Longley-Rice model is the most commonly used model within a frequency band of $40 \mathrm{MHz}$ to $100 \mathrm{GHz}$ over different terrains. Certain modifications over the rudimentary model like an extra urban factor (UF) due to urban clutter near the receiver is also included in this model, but before the outdoor models, let us first discuss the log-distance.

\section{1) Log-distance Path Loss Model}

Log-distance is used to predict the amount of signal propagation loss over a wide range of environments; mostly when the Friis free space model is restricted to unobstructed clear path between the transmitter and receiver [20]. The Friis Free space is a rarely met condition in a radio propagation channel. In a realistic channel, the signals are usually band limited and thus, suffer from fading. Even if the situation is line-of-sight (LOS), there may be reflections from large objects such as building walls and natural features such as hills, mountains, etc. These objects may also cause shadowing leading to a non-line-of-sight (NLOS) situation and slow variations in the path loss around a local mean may be observer when roaming. Smaller objects, foliage, and edges can also cause the signal to scatter resulting to rapid variations in the received signal strength. The Log-distance Path Loss Model path loss model takes this into account and is shown in (4) where the loss is calculated over a distance $d$ [20], [12], [17], [11], [30], [6].

$L_{P}(d)=L_{P}\left(d_{0}\right)+10 n \log \left(\frac{d}{d_{0}}\right)+\chi$

The variable $d_{0}$ is a close-in reference distance, $\chi$ is a zero mean Gaussian distributed random variable expressed in decibel and $n$ is the path loss exponent which represents how fast the path loss increases with distance. If the variable $\chi$ is zero, then (4) results in the log-Normal fading model which shall be called Log Normal Model. To calculate in free space, the variable $n$ will be 2 [20]. The reference distance $\mathrm{d}_{0}$ must be long enough to ensure that the measurements are made in the far-field, i.e. the separation of the antennas is greater than the Fraunhofer or far-field distance. According to [20] and [29], the far-field distance, $d_{f}$, can be calculated using (5).

$d_{f}=\frac{2 D^{2}}{\lambda}$

where $\mathrm{D}$ is the maximum physical linear dimension of the antenna. To ensure that the antenna is in the far-field region

$d_{f} \gg D$
And

$d_{f} \gg \lambda$

must be fulfilled.

When measuring path loss with varying frequencies the equation changes to [21]:

$$
L_{P}(d, f)=L_{P}\left(d_{0}, f\right)+10 n \log \left(\frac{d, f}{d_{0}, f}\right)
$$

\section{2) Okumura Model}

This is often used and the most popular model in the analysis path loss. It is a radio wave propagation model for urban environment and was developed using the data collected in the city of Tokyo, Japan. It is most ideal for use in large cities with many urban structures but not many tall blocking structures. The model served as bases for the Hata models. Okumura model was built into three modes namely urban, suburban and open areas. The model for urban areas was first developed and used as the basis for others such as open areas like farmland, rice fields and other open fields. For the suburban area, the category is village or highway scattered with trees and houses, few obstacles near the mobile. Urban area category is built up city or large town with large buildings and houses with two or more storey or larger village with close houses and tall, thickly grown trees. The Okumura model is expressed as [22], [28], and [24]:

$L_{m}(d B)=L_{F}(d)+A_{m u}(f, d)-G\left(h_{r}\right)-G\left(h_{t}\right)-G_{A R E A}$

where; $L_{m}$ is the signal path loss, $L_{F}(d)$ is free space propagation path loss, $A_{M U}(f, d)$ is median attenuation relative to free space, $G\left(h_{t}\right)$ is the base transceiver station antenna height gain factor, $G\left(h_{r}\right)$ is the mobile antenna height gain factor and $G_{A R E A}$ is the gain due to the type of environment given in suburban, urban and open areas. Correction factors such as the terrain related parameters can be added using a geographical form to allow for street orientation as well as transmission in suburban and open areas and over irregular terrain. The terrain related parameters must be evaluated to determine the various correction factors [1], [27], [24].

\section{3) HATA Model}

This is one of the empirical signal prediction methods in signal propagation. It is based on an extensive series of measurements conducted in and around the city of Tokyo, Japan. The frequency was between $200 \mathrm{MHz}$ and $2 \mathrm{GHz}$. Predictions were made through series of graphs and the most important of which were approximated as a set of formulae by Hata in 1980 [6]. The thoroughness of the works by both Okumura and Hata made them the most widely quoted prediction model in macrocell environments [28] and [29]. They are often regarded as the standard used in judging new approaches [22]. Hata's formulation is limited only to certain range of input parameters and this is only applicable over quasi-smooth terrain. Hata model is expressed mathematically as [24]:

Carrier Frequency, $f_{c}: 150 \mathrm{MHz} \leq f_{c} \leq 1500 \mathrm{MHz}$

Base Station Antenna Height: $30 m \leq h_{b} \leq 200 m$

Mobile Station Antenna Height: $1 m \leq h_{m} \leq 10 m$ 
Transmission Distance: $1 \mathrm{~km} \leq R \leq 20 \mathrm{~km}$

$L_{d B}=A+B \log _{10} R-E \quad$ for Urban Areas

$L_{d B}=A+B \log _{10} R-C$

for Suburban Areas (11)

$L_{d B}=A+B \log _{10} R-D$

for Open Areas

where

$A=69.55+26.16 \log _{10}\left(f_{c}\right)-13.82 \log _{10}\left(h_{b}\right)$,

$B=44.9-6.55 \log _{10}\left(h_{b}\right)$

$C=5.4+2\left[\log _{10}\left(\frac{f_{c}}{28}\right)\right]^{2}$,

$D=40.94+4.78\left[\log _{10}\left(f_{c}\right)\right]^{2}-18.33 \log _{10}\left(f_{c}\right)$

$E=3.2\left[\log _{10}\left(11.75 h_{m}\right)\right]^{2}-4.97$ for large city and $f_{c} \geq$ $300 \mathrm{MHz}$

$E=8.29\left[\log _{10}\left(1.54 h_{m}\right)\right]^{2}$ for large city

and $f_{c}<300 \mathrm{MHz}$

$E=\left[1.1 \log _{10}\left(f_{c}\right)-0.7\right] h_{m}-\left[1.56 \log _{10}\left(f_{c}\right)-0.8\right]$

medium or small cities

where $h_{b}$ is the transmitter height, $h_{m}$ is the receiver height and $f_{c}$ is the transmitting frequency.

4) COST-231

At a frequency of $1845 \mathrm{MHz}$, the path loss is approximately $10 \mathrm{~dB}$ larger than those experienced at $955 \mathrm{MHz}$ all other parameters kept constant [26] and [24]. This model is applicable in the frequency range of 1500$2000 \mathrm{MHz}$ and it can be shown that path loss can be more dramatic at these frequencies than those in $900 \mathrm{MHz}$ range. The model is expressed mathematically as [25], [26], [29], [28], and [24]:

Carrier frequency

BS Antenna Height $\left(h_{b}\right)$

MS Antenna Height $\left(h_{m}\right)$

Transmission Distance (d)

$\left(f_{c}\right) 1500-2000 \mathrm{MHz}$
$30-200 \mathrm{~m}$
$1-10 \mathrm{~m}$
$1-20 \mathrm{~km}$

COST-231 path loss model is expressed as [22], [13], [14], [16], [18] and [24]:

$L(d B)=A+B \log _{10}(d)+C$

where $\mathrm{A}=46.3+33.9 \log _{10}\left(f_{c}\right)-13.28 \log _{10}(h b)-a(h m)$

$B=44.9-6.55 \log _{10}\left(h_{b}\right)$

$\mathrm{C}=0$ for medium city and suburban area

$\mathrm{C}=3$ for metropolitan areas

$a(h m)=3.2\left[\log _{10}\left(11.75 h_{m}\right)\right]^{2}-4.97$ for large city and $f_{c} \geq 300 \mathrm{MHz}$

$a(h m)=8.29\left[\log _{10}\left(1.54 h_{m}\right)\right]^{2}$ for large city and $f_{c}<$ $300 \mathrm{MHz}$

$a(h m)=\left[1.1 \log _{10}\left(f_{c}\right)-0.7\right] h_{m}-\left[1.56 \log _{10}\left(f_{c}\right)-0.8\right]$ for medium or small cities

5) Erceg et al. (1998) Model

Reference [8] noted that the Okumura-Hata model is limited to predictions for the transmission bench- marks it is set for. These include a frequency range of 500 to 1500 MHZ, user distances greater than $1 \mathrm{~km}$ from the base station and antenna heights greater than $30 \mathrm{~m}$.

Therefore, [8] points out that newer communication systems like fixed wireless sets that feature smaller cells, shorter base stations, antenna heights and higher frequencies cannot be successfully predicted using the Okumura-Hata model. [8] and [28], then proposed a model that is to cover the gaps which the Okumura-Hata model could not handle in terms of transmission parameters. The path loss model developed applies to base station antenna heights from 10 to 80 meters; base-to-terminal distances from 0.1 to $8 \mathrm{~km}$ and distinct terrain categories of hilly/moderate to heavy tree density, hilly/light tree density or flat/moderate to heavy tree density and flat/light tree density. The model is presented as:

$P_{L}=\left[A+10\left(a-b h_{b}+\frac{c}{h_{b}}\right) \log _{10}\left(\frac{d}{10}\right)\right]+$

$\left[10 x \sigma y \log _{10}\left(\frac{d}{d_{0}}\right)+\gamma \mu_{\sigma}+\gamma z \sigma_{\sigma}\right]$

where $d \geq d_{0}, \quad A=20 \log _{10}\left(\frac{4 \pi d_{0}}{\lambda}\right), \quad d_{0}=100 \mathrm{~m}, \quad \lambda=$ wavelength in meters, and $h_{b}$ is the base station antenna height in meters

$a, b, c, \mu_{\sigma}, \sigma_{y}, \sigma_{\sigma}$ and $\mathrm{y}$ are all data-derived constants for for different terrain categories. $x, y, z$ are independent zeromean Gaussian variables of unit standard deviation, and $x, z$ vary from cell to cell, while $y$ varies from location to location within each cell.

\section{MATERIALS AND METHOD}

\section{A. Materials}

This work involves the study of the electromagnetic field strength emanating from GSM base transceiver stations (BTS) in Uyo, Nigeria. The BTS are located in different locations such as Itam Road, Udoekong Ekwere Street, and Udo Etuk Inyang Street. The details of these locations will be stated in subsection 3.2.1. The materials used in carrying out the measurements include the following:

1. Radio frequency EMF Strength meter

2. Data Recording Sheet for recording daily measurement results

3. Mobile Phone for monitoring of signal level

4. 3 SIM Cards (MTN, Glo, and Airtel)

5. GPS meter

\section{B. Description of Measurement Tool}

The measurement tool employed in the measurement was radio frequency EMF strength meter. It monitors high frequency radiation in the $50 \mathrm{MHz}$ to $3.5 \mathrm{GHz}$ frequency range, non-directional measurement with triaxial measurement probe and measures for $900 \mathrm{MHz}, 1800 \mathrm{MHz}$, and $2.7 \mathrm{GHz}$. Its units of measurements are $\mathrm{mV} / \mathrm{m}, \mathrm{V} / \mathrm{m}$, $\mathrm{mA} / \mathrm{m}, \mu \mathrm{A} / \mathrm{m}, \mu \mathrm{W} / \mathrm{m}^{2}, \mu \mathrm{W} / \mathrm{cm}^{2}$, etc. Fig. 1 shows the radio frequency EMF strength meter used in carrying out the measurements. 


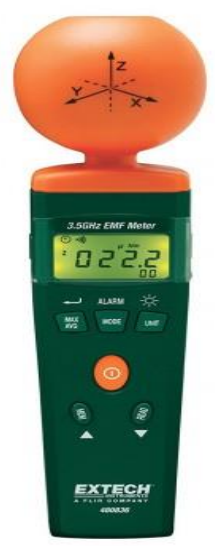

Fig. 1. Radio Frequency Electromagnetic Field Strength Meter

\section{Methods}

In this section, radio frequency electromagnetic field radiation from GSM base transceiver stations were measured in 3 different locations in Uyo, Akwa Ibom State. The study was carried out on the three GSM service providers (MTN, Globacom and Airtel), to determine their radiated electric field strength, magnetic field strength, and power density using Radio frequency EMF Strength Meter. The Radio frequency EMF Strength Meter manufactured by Extech Instrument was used to monitor high frequency radiations from the various BTS.

The measurements in each of the three different locations, namely, Udo Etuk Inyang Street, Udoekong Ekwere Street, and Itam Road, all in Uyo metropolis were carried out through a distance of $2 \mathrm{Km}$ from the base of the BTS mast. The measurements were carried out in 8 months (January, 2017 through August, 2017).

\section{Methods Location of Study Area}

The MTN BTS is located at No 12 Udo Etuk Inyang street, opposite Jamb office, Atiku Abubakar Way, within latitude $5^{\circ} 2$ '10.586" and longitude $7^{\circ} 54^{\prime} 6.741^{\prime \prime}$. The BTS transmitter mast is 33 meters high at a frequency of 1800 $\mathrm{MHz}$ and $3.5 \mathrm{G}$ service.

The Globacom BTS is located at No 3 Udoekong Ekwere street, off IBB way Uyo, within latitude $5^{\circ} 1$ '12.37" and longitude $7^{\circ} 54^{\prime} 27.49$ '. The BTS transmitter mast is 38 meters high and transmits at a frequency of $900 \mathrm{MHz}$.

The Airtel BTS is located at No 16 Itam Road, Uyo within latitude $5^{\circ} 2^{\prime} 44.64^{\prime \prime}$ and longitude $7^{\circ} 53^{\prime} 42.05^{\prime \prime}$. The BTS transmitter mast is 33 meters high and transmits at a frequency of $1800 \mathrm{MHz}$.

These locations are separated far apart from each other as stated in the coordinates. The essence was to ensure proper coverage of the metropolis under study and being that the population density are different from each other. Itam Road has more building and human traffic intensity that the other locations.

\section{E. Data Analysis}

Having obtained the data for the electric field strength, magnetic field strength, and the power density of the transmitted GSM signals in Uyo. It was proper to determine the average measured data for the electric field strength, magnetic field strength, and power density. Fig. 2 through 4 show the analysis of the electric field strength, magnetic field strength, and power density using Matlab plotting tool to determine the equation of line, best fit and standard deviation.

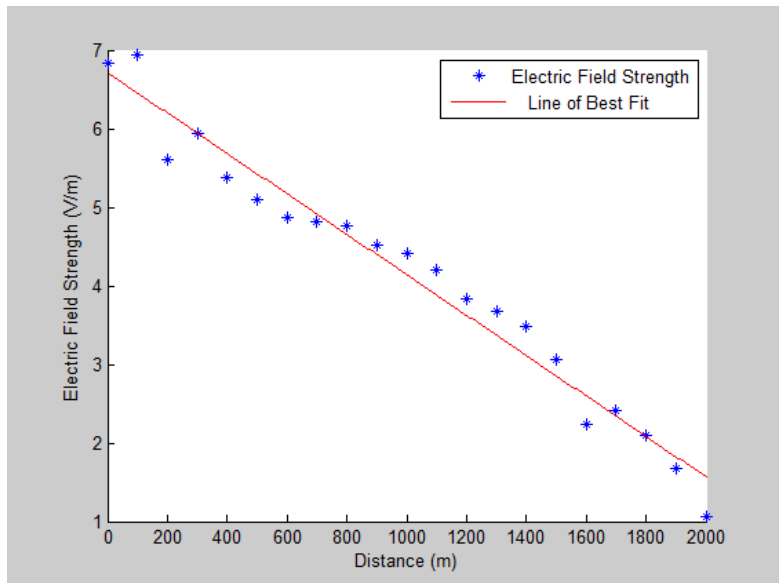

Fig. 2. Scatter point best fit for Electric Field Strength

In Fig. 2, the equation of line was computed as:

$$
y=-0.0026 x+6.71
$$

Standard Deviation $=3.31 \mathrm{~dB}$

This means that for every 1-meter increase in the measurement distance, the electric field strength decreased by $0.0026 \mathrm{~V} / \mathrm{m}$ and at the base of the base of the BTS, the approximate electric field strength is $6.71 \mathrm{~V} / \mathrm{m}$.

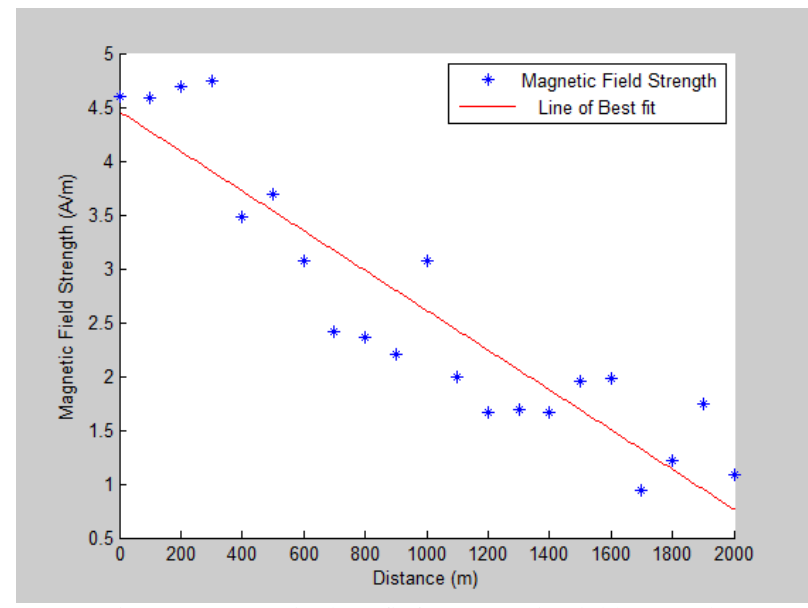

Fig. 3. Scatter point best fit for Magnetic Field Strength

In Fig. 3, the equation of line was computed as:

$$
y=-0.00185 x+4.46
$$

Standard Deviation $=3.36 \mathrm{~dB}$

This means that for every 1 meter increase in the measurement distance, the magnetic field strength decreased by $0.00185 \mathrm{~A} / \mathrm{m}$ and at the base of the base of the BTS, the approximate magnetic field strength is $4.46 \mathrm{~A} / \mathrm{m}$. 


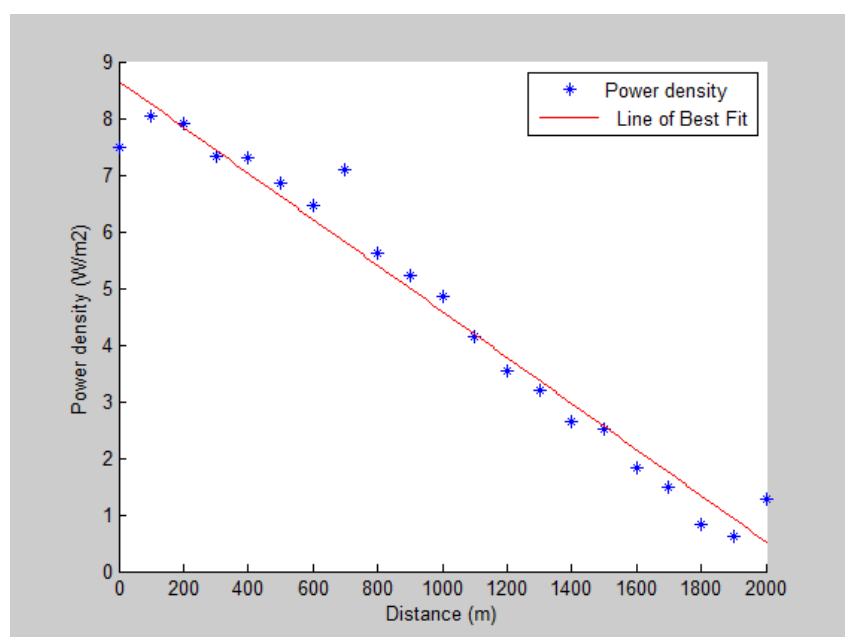

Fig. 4. Scatter point best fit for Power Density

In Fig. 4, the equation of line was computed as:

$$
y=-0.00407 x+8.65
$$

Standard Deviation $=3.36 \mathrm{~dB}$

This means that for every 1 meter increase in the measurement distance, the power density decreased by $0.00407 \mathrm{~W} / \mathrm{m}^{2}$ and at the base of the base of the BTS, the approximate power density is $8.65 \mathrm{~W} / \mathrm{m}^{2}$.

In all the measurements, the standard deviation was between $3.31 \mathrm{~dB}$ and $3.36 \mathrm{~dB}$. This implies that the standard deviation of the measurements are clustered around the mean, indicating high precision.

\section{F. Analysis and Model Development}

\section{1) Signal Strength Analysis}

The results of signal field strength measurements which were taken through three different routes in Uyo are presented in Figs: 5, 6, and 7. It was observed that the GSM transmitter signal strength decreased as the distance increased away from the transmitting antenna.

Some abnormalities or deviation were noticed especially along Udoekong Ekwere Street which could be as a result of the terrain of the environment. Higher elevation or abrupt changes in elevation could be the reason for the zig-zag behaviour of the signal field strength pattern along the street. Also, it can be observed that even though the signal pattern with distance is zig-zag, the signal levels along Udoekong Ekwere street is relatively higher and does not vary much compared to those of other roads. This could also be an advantage of the higher elevation of the terrain. The case was almost the same for Itam Road with regular near zig zag pattern. The reason could be attributed to the increased number of high rise buildings which could be obstructing the signal path way. In Udo Etuk Inyang Street, the electric field strength appears to follow a regular decreasing pattern to a minimum value of $987 \mathrm{mV} / \mathrm{m}$ at a distance of 2000 meters.

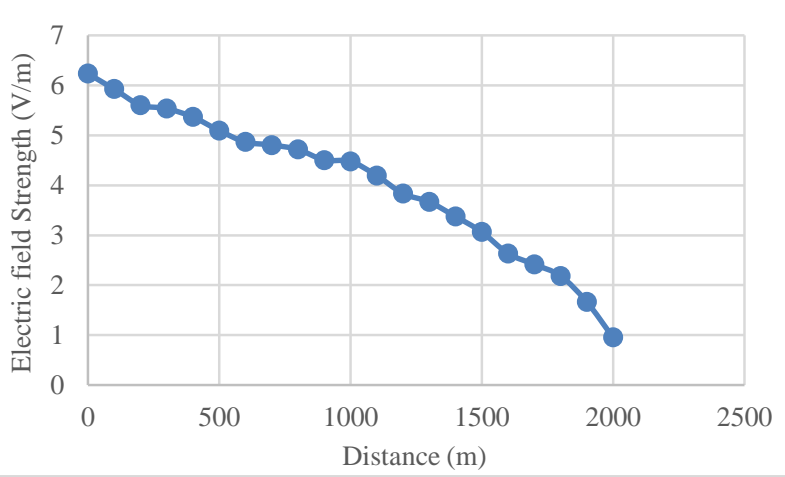

Fig. 5: Signal Field Strength against Distance along Udo Etuk Inyang Street

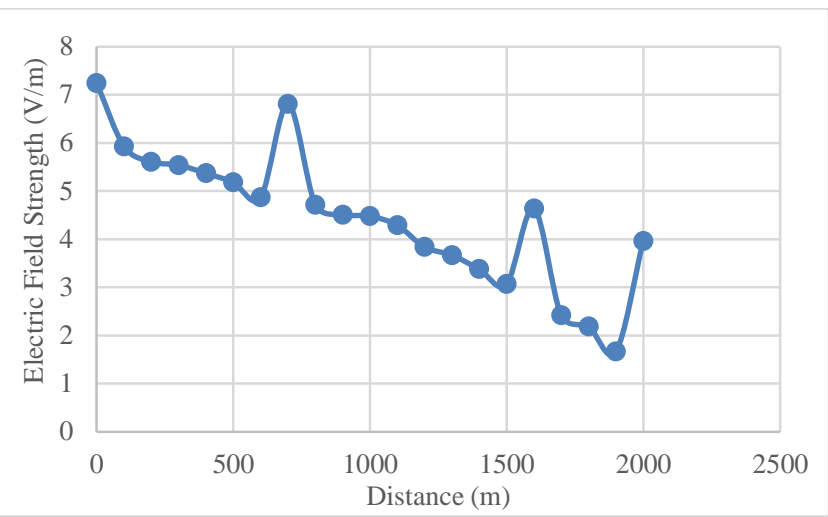

Fig. 6. Signal Field Strength against Distance along Udoekong Ekwere Street

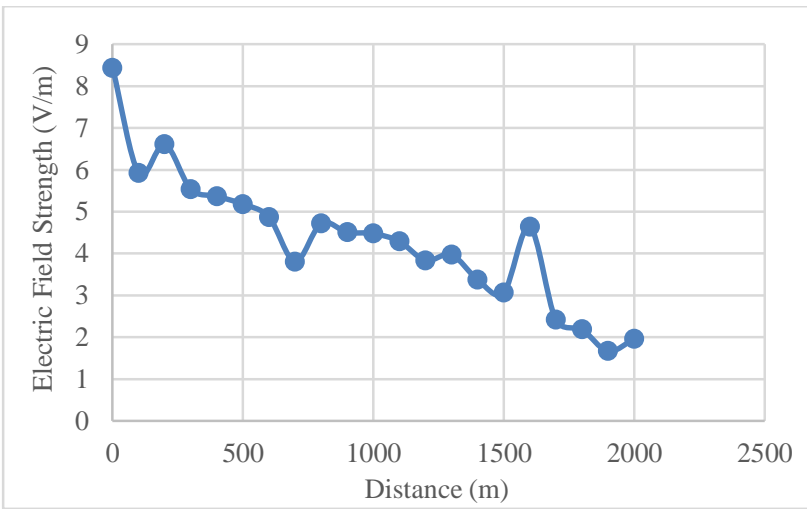

Fig. 7: Signal Field Strength against Distance along Itam Road

\section{2) Radio Wave Propagation Estimated Path Loss}

The corresponding path loss of all field strength measurements taken from different observation points were determined using (15) and (16) [21];

$P_{r}=\frac{G_{r} \lambda^{2} E^{2}}{4 \pi Z_{0}}$

$P_{L}=\frac{P_{t} G_{t} G_{r}}{P_{r}}$

Substituting e (15) into (16) gives:

$P_{L}=\frac{P_{t} G_{t} Z_{0} 4 \pi}{E^{2} \lambda^{2}}$

where $G_{t}$ and $G_{r}$ are transmitter gain and receiver gain respectively, $\lambda$ is the wavelength, $P_{t}$ is the transmitted power, $\mathrm{P}_{\mathrm{r}}$ is the received power, $E$ is the electric field strength, $\mathrm{Z}_{0}$ is the characteristic impedance of free space and $\mathrm{P}_{\mathrm{L}}$ is the path loss. The path loss estimated from 
measurements with corresponding distances for each region were analyzed using Matlab and Excel. Path loss model equations representing the propagation degradation pattern of the GSM signal propagation for Uyo metropolis were developed from which a unified model equation that can be used to predict path loss of GSM signal in Uyo metropolis was developed. From (17), the signal path loss can be expressed in terms of the propagation frequency as:

$P_{L}=\frac{P_{t} G_{t} 16 \pi^{2} d^{2} Z_{0}}{\lambda^{2} E^{2}}$

Where

$\lambda=\frac{v}{f}=\frac{3 \times 10^{8}}{900 \times 10^{6}}=0.333 \mathrm{~m}$

$Z_{0}=377 \Omega$, and $P_{t}=39 \mathrm{~dB}$

Applying this to model $806-896 \mathrm{MHz}, 19 \mathrm{dBi}, 120^{\circ}$ sectoral antenna mounted on a GSM tower whose wavelength is $0.34 \mathrm{~m}$ and effective aperture is $0.1961 \mathrm{~m}^{2}$. The estimated path loss for the three different locations are as shown in figs. 8 through 10 .

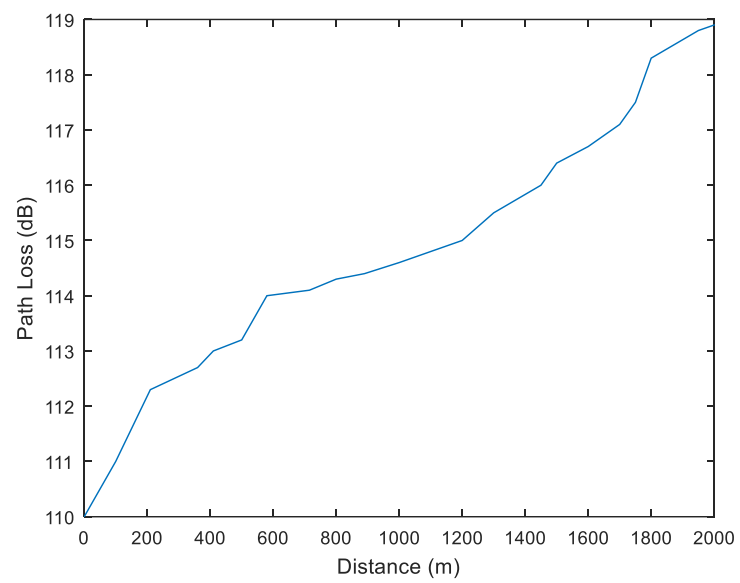

Fig. 8. Estimated Path Loss along Udo Etuk Inyang Street

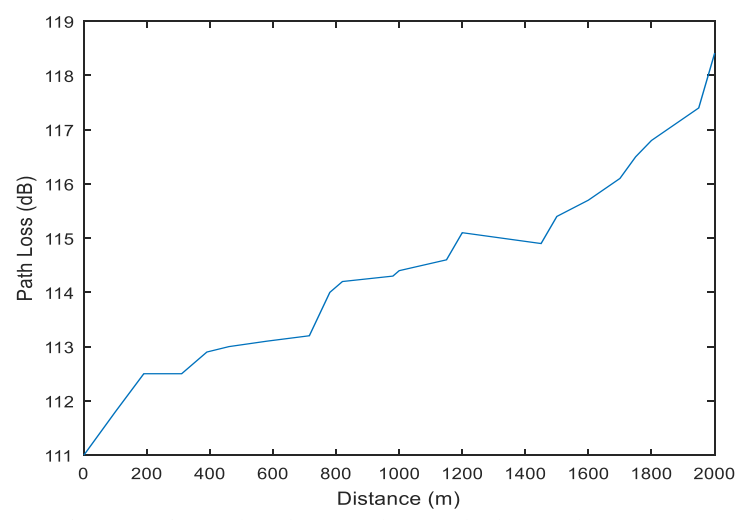

Fig. 9. Estimated Path Loss along Udoekong Ekwere Street

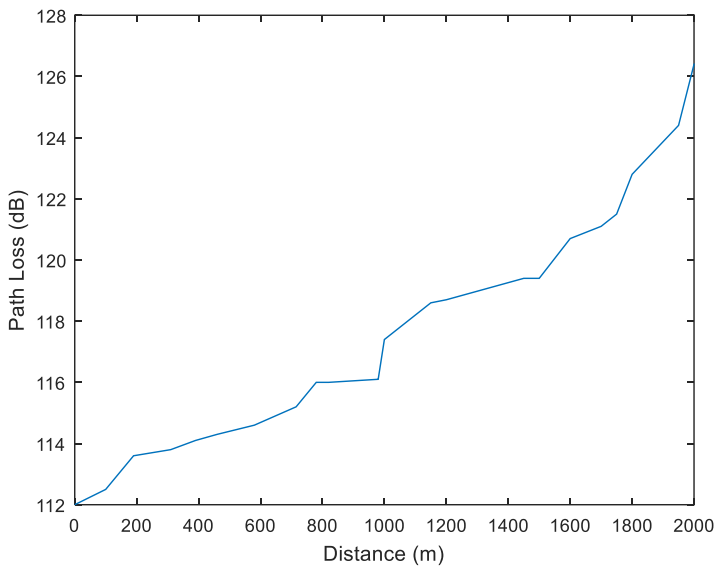

Fig. 10. Estimated Path Loss along Itam Road

\section{G. Model Development}

The estimated path loss from measurements with corresponding distances for each of the three routes taken within Uyo Metropolis were analyzed using ordinary least square (OLS) regression and performed in Microsoft Excel, 2013. The results are as shown in Tables 1 through 3. For each route, a regression line (or equation) was developed to model the pattern of the path loss with distance. In the tables, the $\mathrm{x}$-variables is the distance, while the coefficient of the $\mathrm{x}$-variable is the slope of the regression line, which is an indication of the rate at which the path loss increases with distance from the transmitting antenna.

Table I shows the ordinary least square regression analysis of the line of sight distance with the estimated path loss along route $\mathrm{A}$. The analysis indicated that the correlation coefficient of the regression is approximately 0.99, while the coefficient of determination $\left(\mathrm{R}^{2}\right)$ is approximately 0.99 too. Also, the coefficient of $\mathrm{x}$-variable is 0.34 while the intercept is $111.53 \mathrm{~dB}$ as shown in the table. This shows that the developed regression line (equation) for Udo Etuk Inyang Street matches very well with the estimated path loss.

Therefore, the developed path loss model for Udo Etuk Inyang Street will be:

$P_{L}(d B)=111.52+0.34 d_{(m)}$

Table II shows the ordinary least square regression analysis of the distance with the estimated path loss along Udoekong Ekwere Street. The analysis indicated that the correlation coefficient of the regression is approximately 0.99, while the coefficient of determination $\left(\mathrm{R}^{2}\right)$ is approximately 0.99 too. Also, the coefficient of $\mathrm{x}$-variable is 0.34 while the intercept is $111.10 \mathrm{~dB}$ as shown in the table. This shows that the developed regression line (equation) for Udoekong Ekwere Street matches very well with the estimated path loss.

Therefore, the developed path loss model for Udoekong Ekwere Street will be:

$$
P_{L}(d B)=111.10+0.34 d_{(m)}
$$


Table 3 shows the ordinary least square regression analysis of the distance with the estimated path loss along
Itam Road.

TABLE I: OLS REGRESSION RESULT ALONG UDO ETUK INYANG STREET

\begin{tabular}{|c|c|c|c|c|c|c|c|c|}
\hline Regression Statistics & & & & & & & & \\
\hline Multiple R & 0.994010308 & & & & & & & \\
\hline R Square & 0.988056492 & & & & & & & \\
\hline Adjusted R Square & 0.987427886 & & & & & & & \\
\hline Observations & 21 & & & & & & & \\
\hline \multicolumn{9}{|l|}{ ANOVA } \\
\hline & $d f$ & $S S$ & $M S$ & $F$ & Significance $F$ & & & \\
\hline Regression & 1 & 93.71954175 & 93.71954175 & 1571.822 & $9.81667 \mathrm{E}-20$ & & & \\
\hline Residual & 19 & 1.13287053 & 0.059624765 & & & & & \\
\hline Total & 20 & 94.85241228 & & & & & & \\
\hline \multirow{3}{*}{ Intercept X Variable 1} & Coefficients & Standard Error & t Stat & $P$-value & Lower 95\% & Upper $95 \%$ & Lower $95.0 \%$ & Upper $95.0 \%$ \\
\hline & 111.528761 & 0.111433291 & 1000.856742 & $2.5 \mathrm{E}-46$ & 111.2955284 & 111.761994 & 111.2955284 & 111.7619935 \\
\hline & 0.338787726 & 0.008545273 & 39.64621566 & $9.82 \mathrm{E}-20$ & 0.320902265 & 0.35667319 & 0.320902265 & 0.356673188 \\
\hline
\end{tabular}

The analysis indicated that the correlation coefficient of the regression is approximately 0.99 , while the coefficient of determination $\left(\mathrm{R}^{2}\right)$ is approximately 0.99 too. Also, the coefficient of $\mathrm{X}$-variable is 0.73 while the intercept is 111.28 $\mathrm{dB}$ as shown in the table. This shows that the developed regression line (equation) for Itam Road matches very well with the estimated path loss.

Therefore, the developed path loss model for Itam Road will be:

$$
P_{L}(d B)=111.28+0.73 d_{(m)}
$$

TABLE II: OLS REGRESSION RESULT ALONG UDOEKONG EKWERE STREET

\begin{tabular}{|c|c|c|c|c|c|c|c|c|}
\hline Regression Statistics & & & & & & & & \\
\hline Multiple R & 0.993225234 & & & & & & & \\
\hline R Square & 0.986496365 & & & & & & & \\
\hline Adjusted R Square & 0.985882563 & & & & & & & \\
\hline Standard Error & 0.214779824 & & & & & & & \\
\hline Observations & 24 & & & & & & & \\
\hline \multicolumn{9}{|l|}{ ANOVA } \\
\hline & $d f$ & $S S$ & $M S$ & $F$ & Significance $F$ & & & \\
\hline Regression & 1 & 74.14031513 & 74.14032 & 1607.191 & $4.61 \mathrm{E}-22$ & & & \\
\hline Residual & 22 & 1.0148682 & 0.04613 & & & & & \\
\hline Total & 23 & 75.15518333 & & & & & & \\
\hline \multirow{3}{*}{ Intercept X Variable 1} & Coefficients & Standard Error & $t$ Stat & $P$-value & Lower 95\% & Upper 95\% & Lower $95.0 \%$ & Upper $95.0 \%$ \\
\hline & 111.1046592 & 0.097831529 & 1135.673 & $5.98 \mathrm{E}-54$ & 110.9018 & 111.3075 & 110.9018 & 111.3075 \\
\hline & 0.343139827 & 0.008559283 & 40.08979 & 4.61E-22 & 0.325389 & 0.360891 & 0.325389 & 0.360891 \\
\hline
\end{tabular}

Equations (20) through (22) represents the signal propagation attenuation pattern for GSM signal propagation along the three routes in Uyo metropolis. Considering the average of the signal path loss for the three routes, a unified path loss model for Uyo metropolis can be expressed as:

$$
P_{L}(d B)=111.30+0.47 d_{(m)}
$$

Equation (23) can be used to predict the GSM signal path loss for Uyo metropolis.

\begin{tabular}{|c|c|c|c|c|c|c|c|c|}
\hline Regression Statistics & & & & & & & & \\
\hline Multiple R & 0.994021331 & & & & & & & \\
\hline R Square & 0.988078407 & & & & & & & \\
\hline Adjusted R Square & 0.987333308 & & & & & & & \\
\hline Standard Error & 0.474701364 & & & & & & & \\
\hline Observations & 18 & & & & & & & \\
\hline \multicolumn{9}{|l|}{ ANOVA } \\
\hline & $d f$ & $S S$ & $M S$ & $F$ & Significance $F$ & & & \\
\hline Regression & 1 & 298.8257823 & 298.8258 & 1326.1025 & $8.05539 \mathrm{E}-17$ & & & \\
\hline Residual & 16 & 3.605462163 & 0.225341 & & & & & \\
\hline Total & 17 & 302.4312444 & & & & & & \\
\hline \multirow{3}{*}{ Intercept X Variable 1} & Coefficients & Standard Error & $t$ Stat & $P$-value & Lower 95\% & Upper 95\% & Lower $95.0 \%$ & Upper $95.0 \%$ \\
\hline & 111.2785906 & 0.224695867 & 495.2409 & $6.438 \mathrm{E}-35$ & 110.8022567 & 111.761994 & 111.2955284 & 111.7619935 \\
\hline & 0.473266430 & 0.020119467 & 36.41569 & $8.055 \mathrm{E}-17$ & 0.690012939 & 0.35667319 & 0.320902265 & 0.356673188 \\
\hline
\end{tabular}

TABLE III: OLS REGRESSION RESULT ALONG ITAM ROAD

\section{H. Comparison of the Developed Path Loss Model with other Empirical Models}

The performance of existing conventional models: Okumura-Hata, COST-Hata, Egli, and Route D models were also evaluated with distance and compared to the developed model. Path loss for each model was calculated and compared with that of the developed model. The developed model showed a gradual path loss over a distance of $2 \mathrm{~km}$ which is similar to the Route D model. Though the Okumura model and the COST-231 Hata model had almost the same amount of path loss trend, the results also showed very close 
loss value. At a distance of 10 meters from the BTS, the path loss for the four models were almost equal as shown in Fig. 11. The figure. shows that the COST-231 and Okumura models have the highest differing path loss with the developed model, this can be attributed to the differences in terrain and topology of the different locations.

Since, the path loss is almost equal at a distance close to the BTS for all the models considered, it can be concluded that the developed model will offer good approximation for predicting signal loss over certain distance for Uyo metropolis.

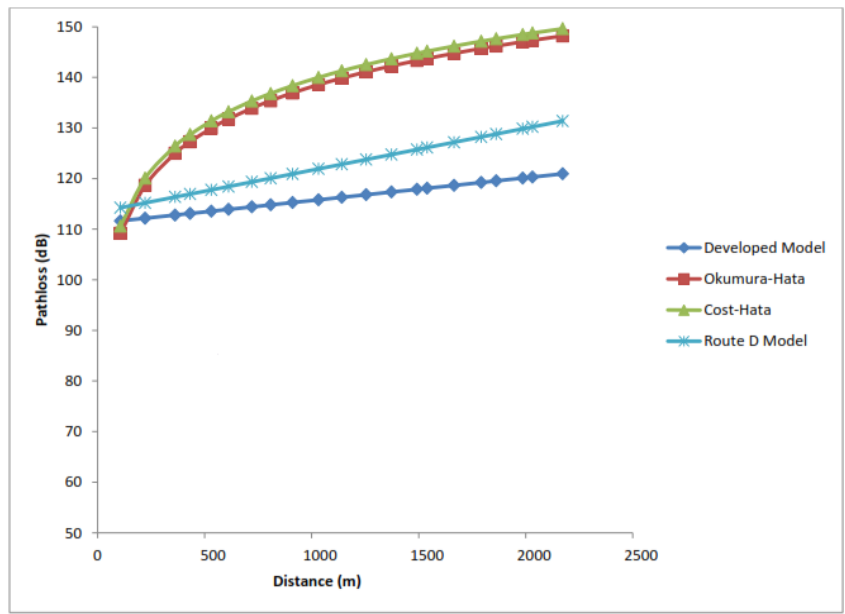

Fig. 11. Comparison of the Developed Model with other existing Empirical Models.

\section{CONCLUSION AND RECOMMENDATION}

\section{A. Conclusion}

This research work has been able to develop a GSM model for radio wave propagation model in Uyo metropolis for path loss prediction within the city, using three different BTS signal as the reference signal. This can form basis or platform in planning and design of wireless communication systems. The terrain can be classified as both rough irregular terrain and gentle plain terrain. Measurements of signal strength show that quality of reception of the GSM signals within the metropolis is expected to be satisfactory. The developed path loss model is a good representation of the obtained measurement values. Also, measurements showed that western part of Itam Road exhibited a remarkably different characteristic thereby necessitated a separate but related developed model.

Performance of three conventional empirical propagation models: Okumura-Hata model, COST-Hata model, and Route D model were also evaluated in predicting the path loss in Uyo. The developed model was compared with the predictions made by the three propagation models used.

The result shows that Route $\mathrm{D}$ model has a better comparison factor with the developed model while Okumura-Hata and Cost-Hata have the same but more losses as the distance is increased. In all the measurements, the standard deviation varied between 3.31 and 3.36.

\section{B. Contribution to knowledge}

This work offers the following contribution to knowledge:
1. It has developed a path loss model for predicting GSM network for Uyo metropolis.

2. It has analyzed the GSM signal variation which can serve as a working document for the telecommunication network providers and Nigeria Communications Commission.

3. It has shown that residents dwelling close to the BTS can experience its electromagnetic impact than those afar off.

\section{Recommendation}

The path loss model developed in this research work is for GSM signal only. Therefore, it is recommended that a similar work should be carried out for other wireless networks including television broadcasting.

The signal strength measurement for this research was done during the dry season of the year therefore it is also recommended that a similar research should be done for rainy season.

The path loss model developed in this work is recommended to be used for GSM wireless communication link in Uyo, Nigeria and similar environment.

Also, frequent measurement of signal strength should be carried out in a developing semi urban environment like Uyo where erection of buildings and other physical structures is rapid to account for its effect on the quality of wireless signal.

Finally, measurement based path loss model should first be considered while planning and developing a wireless communication link rather than relying solely on conventional empirical models only.

\section{REFERENCES}

[1] V.S. Abhayawardhana, I.J. Wassell, D. Crosby, M.P. Sellars, and M.G. Brown, "Comparison of Empirical Propagation Path Loss Models for Fixed Wireless Access Systems", IEEE 61st Vehicular Technology Conference, 2005-Spring, 1: pp. 73-77, 2005.

[2] O.T. Ayekomilogbon, J.O. Famoriji, and Y.O. Olasoji, "Evaluation and Modeling of UHF Radio Wave Propagation in a Forested Environment", International Journal of Engineering and Innovative Technology, vol. 2, No. 12, pp. 101-106, 2013.

[3] N. Blaunstein, D. Censor, and D. Katz, "Radio Propagation in Rural Residential Areas with Vegetation", Progress in Electromagnetic Research, PIER 40, pp. 131-153, 2003.

[4] P. Elechi and P.O. Otasowie, "Determination of Path Loss Exponent for GSM Wireless Access in Rivers State using Building Penetration Loss", The Mediterranean journal of Electronic and Communications, vol. 11 , no. 1, pp. 822-830, 2015.

[5] P. Elechi and P.O. Otasowie, "Path Loss Prediction Model for GSM Fixed Wireless Access", European Journal of Engineering Research and Science, vol. 1, no. 1, pp. 7-11, 2016.

[6] P. Elechi and P.O. Otasowie, "Comparison of Empirical Path Loss Models with Building Penetration Path Loss Model", International Journal on Communication Antenna and Propagation, vol. 6, no. 2, pp. 854-861, 2016. https://doi.org/10.15866/irecap.v6i2.8013

[7] J. Epstein and D.W. Peterson, "An Experimental Study of Wave Propagation at $850 \mathrm{Mc} / \mathrm{s}$ ", Proceedings of IRE, vol. 41, no. 5, pp. 595 $611,1953$.

[8] V. Erceg, L.J. Greenstein, S. Tjandra, S.R. Parkoff, A. Gupta, B Kulic, A. Julius, and R. Jastrzab, "An empirically-based Path Loss Model for Wireless Channels in Suburban Environments", IEEE Transactions on Antennas and Propagation, vol. 9, pp. 922-927, 1998.

[9] J.O. Famoriji and Y.O. Olasoji, "Radio Frequency Propagation Mechanisms and Empirical Models for Hilly Areas", International Journal of Electrical and Computer Engineering, vol. 3, no. 3, pp. 372-376, 2013.

[10] J.O. Famoriji and Y.O. Olasoji, "UHF Radio Frequency Propagation Model for Akure Metropolis", Research Journal of Engineering Sciences, vol. 2, no. 5, pp. 6-10, 2013. 
[11] R.L. Freeman, "Telecommunication System Engineering", 4th Edition, John Wiley and Sons Inc. Publication, pp. 189-205, 2005.

[12] H. Hashemi (1993): The Indoor Radio Propagation Channel, Proc. IEEE, 81(7): 943-968

[13] J. Hata and B. Davidson, “A Report on Technology Independent Methodology for the Modeling Simulation and Empirical Verification of Wireless Communications System Performance in Noise and Interference Limited Systems Operating on Frequencies between 30 and 1500MHz”, IEEE Vehicular Technology Propagation Committee, TIA TR8 Working Group, 1997.

[14] International Telecommunications Union, ITU-R Recommendation 527-3: Electrical Characteristics of the Surface of the Earth, Geneva, 1992.

[15] J. Isabona and C.C. Konyeha, "Urban Area Path loss Propagation Prediction and Optimisation using Hata Model at $800 \mathrm{MHz}$, IOSR Journal of Applied Physics, vol. 3, no. 4, pp. 8-10, 2013.

[16] A.A. Moinuddin and S. Singh, "Accurate Path Loss Prediction in Wireless Environment, The Institution of Engineers (India), vol. 88, no. 1, pp. 9-13, 2007

[17] D. Moldkar, "Review on Radio Propagation into and within Buildings, microwaves and Antennas and Propagation", IEE Proc. H, vol. 138, no. 1, pp. 1452-1459, 1991

[18] S.E. Odongo, "Heuristic for Wireless Metropolitan Area Network Optimum Performance: Focus on Terrain”, M. Sc. dissertation, Data Communication and Software Engineering of Makarere University, Kenya. (Unpublished), 2008.

[19] F.K. Opara, U.G. Adigwe, and C.E. Agbaraji, "Investigation and Analysis on Electromagnetic Radiation from Cellular Base Station Transmitter and the Implications to Human Body", Journal of Environment and Ecology, vol. 5, no. 1, pp. 46-60, 2014.

[20] T.S. Rappaport, "Wireless Communications: Principles and Practice", 2nd ed. Pearson Education PTE Ltd, Singapore, pp. 105-167, 2003.

[21] T.S. Rappaport, "Wireless Communications: Principles and Practice", Upper Saddle River, NJ: Prentice Hall PTR, pp. 75-92, 2002.

[22] S.R. Saunders and A. Aragon-Zavala, "Antennas and Propagation for Wireless Communication System", 2nd Ed., John Wiley and Sons Publishers, pp. 5-135, 2007.

[23] O. Shoewu and F.O. Edeko, "Analysis of Radio Wave Propagation in Lagos Environs", American Journal of Scientific and Industrial Research, vol. 2, no. 3, pp. 438-455, 2011.

[24] Y. Singh, "Comparison of Okumura, Hata and COST-231 Models on the Basis of Path Loss and Signal Strength", International Journal of Computer Applications, vol. 59, no. 11, pp. 9-13, 2012.

[25] M.A. Masud, M. Samsuzzaman, and M.A. Rahman, "Bit Error Rate Performance Analysis on Modulation Techniques of Wideband Code Division Multiple Access", Journal of Telecommunication, vol. 1, no. 2, pp. 22-29, 2010

[26] A. Katariya, A. Yadav, N. Jain, and G. Tomar, "BER Performance Criteria based on Standard IEEE 802.11a for OFDM in Multipath Fading Environment", International Conference on Computational Intelligence and Communication Systems, pp. 452-459, 2011.

[27] M. Kumar, V. Kumar, and S. Malik, "Performance and Analysis of Propagation Models for Predicting RSS for Efficient Handoff", International Journal of Advanced Scientific Research and Technology, vol. 1, no. 2, pp. 54-61, 2012.

[28] P. Elechi and P.O. Otasowie, "Determination of GSM Signal Penetration Loss in Some Selected Buildings in Rivers State", Nigeria, Nigerian Journal of Technology (NIJOTECH), vol. 34, No. 3, pp. 609-615, 2015.

[29] P. Elechi, "An Improved Signal Penetration Path Loss Model for GSM Network", Journal of Electrical Electronic System, vol. 4, No. 3, pp. 84-90, 2015.
[30] P. Elechi and P.O. Otasowie, "Analysis of a Developed Building Penetration Path Loss Model for GSM Wireless Access", International Journal of Engineering Research and General Science, vol. 3, No. 6, pp. 898-909, 2015.

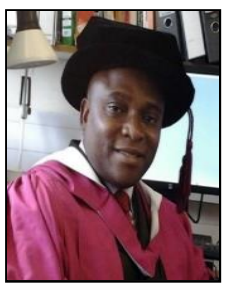

Orike Sunny received his B. Tech. in Computer Engineering from Rivers State University of Science and Technology in 1998, M. Sc. in Computing (Software Technology) from Robert Gordon University, Aberdeen, United Kingdom, M. Phil in Computational Intelligence from Robert Gordon University, Aberdeen, United Kingdom in 2008 and Ph.D in Artificial Intelligence from Heriot-Watt University, Edinburgh, United Kingdom in 2015. He is an active member of several professional bodies, including Council for the Regulation of Engineering in Nigeria (COREN), Nigeria Institution of Electrical Electronic Engineers (NIEEE) and International Association of Engineers (IAENG). Dr. Sunny Orike is a Lecturer and currently the Head, Department of Electrical \& Computer Engineering, Rivers State University, Port Harcourt, Nigeria. Dr. Orike acts as a reviewer to the journals: Journal of Applied Soft Computing, Journal of Control and Intelligent Systems, International Journal of Electrical Power and Energy Systems, Journal of Computer Science and its Applications, and African Advances in Mathematics and Computer Science; a Facilitator with the National Open University of Nigeria, and External Assessor for Port Harcourt Polytechnic. Dr. Orike is married with three children, and can be reached on: orike.sunny@ust.edu.ng, and $+2348033988451$

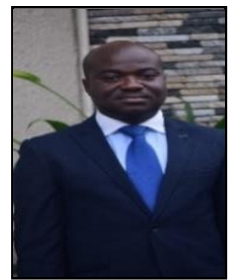

Elechi Promise received his B.Eng and M.Eng degrees in Electrical/Electronic Engineering from University of Port Harcourt, Choba, Rivers State, Nigeria in 2006 and 2011 respectively. $\mathrm{He}$ is currently a Ph.D Student in Electronic and Telecommunication Engineering of University of Benin. He is a corporate member of the Nigerian Society of Engineers (NSE), International Association of Engineers (IAEng), Institute of Engineering and Technology (IET), and Nigerian Institution of Electrical/Electronic Engineers (NIEEE). He is also a registered practicing Engineer with the Council for the Regulation of Engineering in Nigeria (COREN). His current research interest is on Radio Propagation for Mobile Communications, GSM Technology, Microwave Propagation, Signal Analysis, NanoTechnology and ICT. He is currently a Lecturer in the Department of Electrical and Computer Engineering, Rivers State University, Port Harcourt, Nigeria. Elechi can be reached on elechi.promise@ust.edu.ng, and +2348035476478.

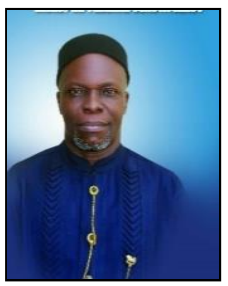

Ekanem Iboro Asuquo received his HND and PGD in Electrical Engineering from The Polythechnic, Calabar and Rivers State University of Science and Technology, Port Harcourt in 1981 and 2010 respectively. He is currently an M.Tech student in Electrical Engineering (Telecommunication Engineering) of Rivers State University, Port Harcourt. He is a corporate member of the Nigerian Society of Engineers (NSE) and a registered practicing Engineer with the Council for the Regulation of Engineering in Nigeria (COREN). He is currently a member, Nigeria's House of Representatives and chairman, House of Representatives' Ad-Hoc Committee to Investigate the Health Implications of Mounting of Telecommunications Mast Close to Buildings. 